\title{
DESIGN OF FOOTSTEP POWER GENERATION SYSTEM
}

\author{
Piyush Chauhan', Akash Kumar², Sushma Sareen ${ }^{3}$, Harshdeep Singh ${ }^{4}$, \\ Kartik Poonia ${ }^{5}$, Ashish Kush ${ }^{6}$ \\ ${ }_{1,2,3,4,5}$ Student, Department of Civil Engineering, Dronacharya Group of Institutions, \\ Greater Noida, Uttar Pradesh \\ ${ }^{6}$ Head of department, Civil Engineering, Dronacharya Group of Institutions, \\ Greater Noida, Uttar Pradesh
}

Article DOI: https://doi.org/10.36713/epra7965

DOI No: 10.36713/epra7965

\begin{abstract}
In this project, we're generating electrical energy by a non-conventional approach, simply by walking on the footsteps. Non-conventional methods for energy generation is very much required in the present scenario. Here, we're generating electricity with the assist of crankshaft arrangement. For its proper functioning, such that it converts force into electric power, the mechanism includes crankshaft mechanism, hydraulics, generator and a battery. We have referred to several applications with extensions for the future. Additionally, we have represented the simulation of the footstep energy generator using the AutoCAD software. This project is very cost effective and is easy to set up in a populated place like stations, bus stands, in shopping malls, and in many other locations.
\end{abstract}

\section{INTRODUCTION}

1.1 Impact on environment from generation of electricity.

With the decline in availability of traditional electricity generation resources, there is a need to find alternate electricity resources. Almost all of the state energy departments in the world are not able to deliver the power in line as much as it is required. The power produced via these organizations isn't always enough for domestic utilities; in such essential state of affairs it is very hard to divert the power for different public desires.

Currently, the primary sources of energy in the world are fossil fuels such as coal, oil, and natural gas. Total worldwide gross production of electricity in 2018 was 25,082 TWh. Sources of electricity includes coal and peat $38.3 \%$, natural gas $23.1 \%$, hydroelectric $16.6 \%$, nuclear power $10.4 \%$, oil $3.7 \%$, solar $2 \%$ wind $5 \%$, biomass and waste $2.3 \%$. Unfortunately, fossil fuels are non-renewable resources created over the course of millions of years, far beneath the Earth's surface. When these finite resources are gone, they're gone. [1]

The rate at which we're using fossil fuels is too fast. If we don't make a drastic and immediate change in how we're using them, they could be potentially depleted within our children's lifetime. On the other hand, renewable energy comes from virtually inexhaustible sources. Using these natural resources allows us to conserve and extend the lifespan of our nonrenewable resources. 


\section{EPRA International Journal of Research and Development (IJRD) Volume: 6 | Issue: 7 | July 2021

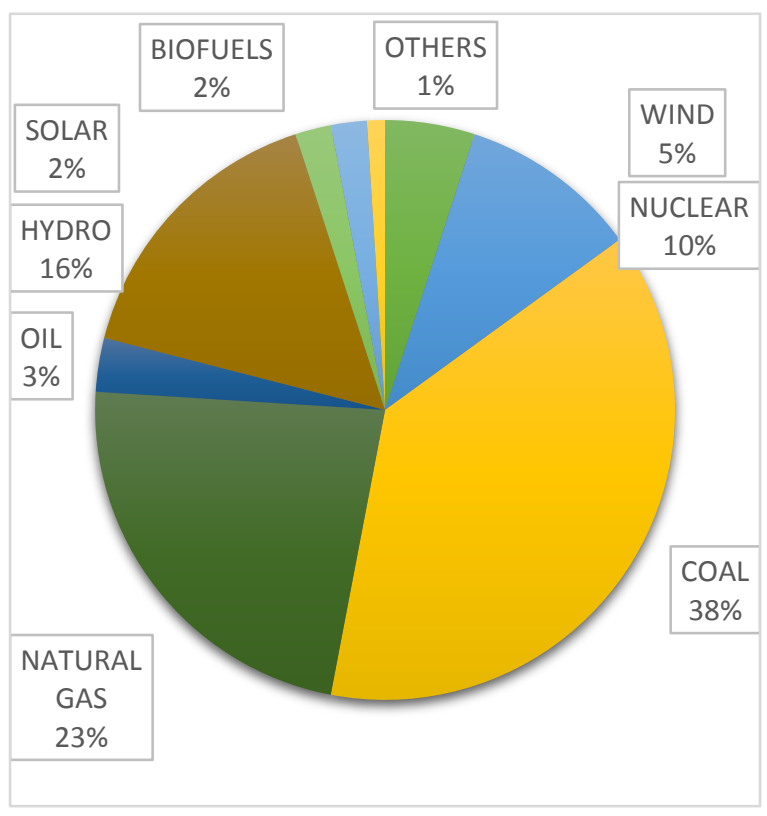

Figure 1 Sources of Generation of

Electricity around the Globe (2018)

Even worse than depletion might be that fossil fuels have an extremely negative impact on the environment. The top cause of carbon emissions in the world comes from electricity generation produced by burning fossil fuels in nonrenewable power plants. Carbon dioxide and other greenhouse gas emissions lead to global warming and other forms of climate change, which can lead to:'

1. Acid rain

2. Smog

3. Soot

4. Toxic air emissions

5. Congenital disabilities

6. Cancer

7. Other severe health-related conditions

8. Changes in sea level

9. Cold snaps

10. Droughts

11. Hurricanes

12. Melting glaciers

13. Wildfires
1.2 Adapting Renewable \& Non-Conventional resources.

We all are aware of the need of electricity in today's world, the shortage of electricity is still a major problem in many remote parts of the world, where the electrical lines have still not reached, or there is no supply in them. Because of this, roughly $13 \%$ of the world, or approx. 940 million people do not have access to electricity globally. [2]

Switching to renewable energy sources and other non-conventional methods can positively impact the environment by slowing climate change by reducing the carbon footprint of coal and other fossil fuels, and can be a good alternative to provide electricity where the supply of electricity is still a big problem, like in the villages or other remote parts of the world. This positive environmental impact is where the terms green energy and clean energy come from.

The International Renewable Energy Agency (IRENA) published a report in 2020 that shows renewable power is becoming increasingly cheaper than fossil fuel for electricity generation. Using solar photovoltaics and onshore wind to replace coal could save up to $\$ 23$ billion in annual power system costs and reduce yearly carbon dioxide emissions by 1.8 gigatons. Solar PV costs are now one-fifth lower than the least expensive fossil-fuel source, and onshore wind power offers even greater savings. Nuclear, hydro, geothermal, and biomass energies are making their way into the financially competitive spotlight as well, significantly based on location. [3]

\section{PROBLEM STATEMENT \& OBJECTIVE}

2.1 Problem statement: Rising pollution levels in the atmosphere and the shortage of electricity in various parts of the world, with a daily increase in demand of electricity is leading all of us to prefer non-conventional resources, such as solar and wind powered mechanism, but they are still an expensive affair for many, furthermore availability of sunlight is poor especially in rainy \& winter seasons, as a result it is not reliable. Consequently, an opportunity for a cheap approach needs to be implemented for the generation of electricity. 


\section{EPRA International Journal of Research and Development (IJRD) Volume: 6 | Issue: 7 | July 2021 \\ - Peer Reviewed Journal}

2.2 Objective: This work has been taken up, that aims to generate electricity from footsteps mechanism. This technology described on this venture document is far clean, continuous, secure, and does not pollute the environment and thus might be a really viable opportunity within the days to come. The entire human strength is being wasted, which should be utilized in our vision, that can result

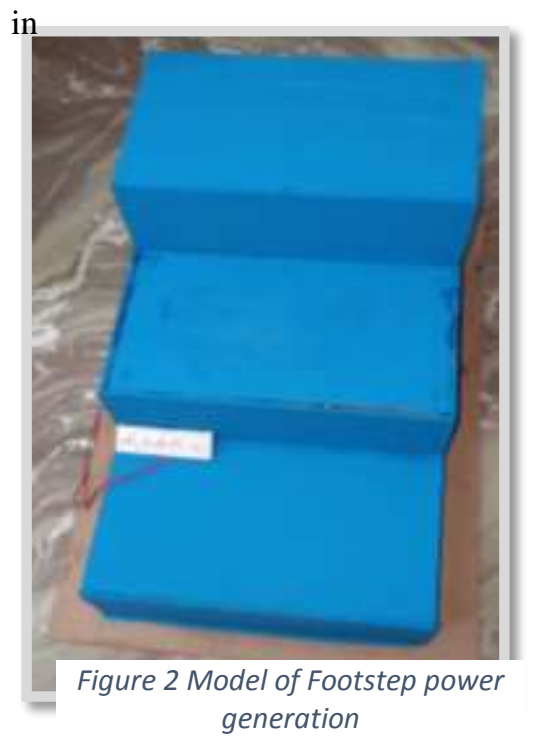

splendid invention. An energy-producing platform can be a very beneficial asset in crowded locations. As the crowd is increasing, the load implemented on the footsteps will generate a nonstop supply of power, which can be stored and can be applied in various applications

\section{COMPONENTS USED}

3.1. Frame: Frame is the main structure of the system. The frame needs to endure all the weight of the human and also to keep the exploratory setup in its place.

3.2. Crank shaft: A crank shaft mechanism is used in the system, where the shaft is connected with the upper plate of the footstep, and the other part is connected via a crank mechanism with the main rod, which together will ensure a full and smooth rotational movement. [7]

3.3. Belt \& Pulley mechanism: A belt and pulley is infused to the main rod, where the bigger wheel is attached to the main rod, which is then connected to a small wheel via a belt. Both the wheels have a smooth outer surface for optimum movement of belt. [8]

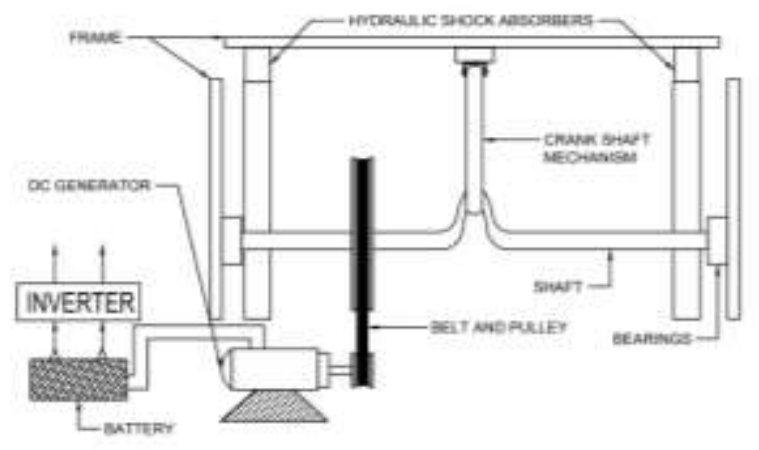

Figure 3 Block diagram of Footstep Power Generation

3.4. Hydraulic Shock Absorbers: A shock absorber or damper is a mechanical or hydraulic device designed to absorb and damp shock impulses. For that purpose, fluid in the shock absorber is forced to flow through restricted outlets and valve systems, thus generating hydraulic resistance.

3.5. Bearings: Bearings allow relative movement between different parts. To lessen the wear \& tear caused by the frictional obstructions, and to divert the warmth produced, a layer of liquid (known as ointment) might be given.

3.6. Shaft: It is a rod supporting and connecting the crankshaft to the gear mechanism. This shaft is free to rotate as it is connected to bearings at both ends. A high carbon alloy steel that is EN8/ AISI 1045 was selected as material for shaft.

3.7. D.C. Generator: It converts mechanical rotation into electric power. It's a device that makes direct current into electric power using electromagnetism. Its work on a Faradays law. It uses turning curl of wire and attractive fields to change over mechanical revolution into beating direct current.

3.8. Battery: A battery is connected via the wires to the dc generator which can store the electricity produced, and this stored power can be used in many applications.

3.9. Inverter: It's an electric device that convert the direct current (DC) into alternating current (AC). The design of specific circuity depends by the input voltage, output voltage, frequency and overall power handling capacity. The inverter does not provide power but the power is provided with the help of DC source. 


\section{EPRA International Journal of Research and Development (IJRD) Volume: 6 | Issue: 7 | July 2021 \\ - Peer Reviewed Journal}

\section{WORKING OF THE PROJECT}

4.1 Working principle:

4.1.1 Crankshaft mechanism: In this system, we have used the crankshaft mechanism, that converts the reciprocating motion into rotating motion.

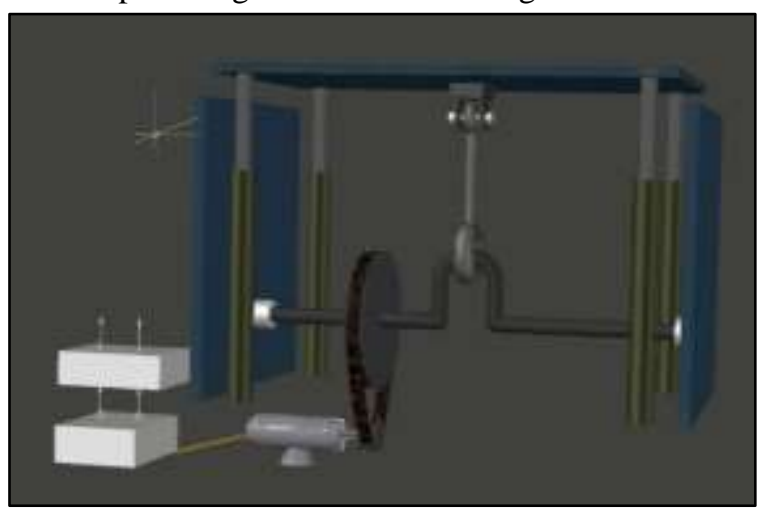

Figure 4 3D model of Footstep power generation

Here the pressing down of the footstep with one or both feet, causes a rocking motion. This movement can then be stored as rotational motion.

4.1.2 Belt \& Pulley mechanism: This rotational motion is transferred to the attached wheel of the belt and pulley mechanism. As this wheel is always mounted on a rotary part of the energy source i.e. the main rod, power can be transferred through a belt to the smaller wheel, which then can be transferred to the device. It serves as a source of power to that device. A belt is the cheapest form. It's a loop of flexible material used to link two or more rotating shafts mechanically, often in a parallel form. These belts may be used as a source of motion as it transmits power more efficiently.

4.1.3 DC generator: This transmission of power to the dynamo results in the generation of electricity. This dynamo is used to convert mechanical energy into electrical energy. The electric dynamo uses rotating coils of wire and magnetic fields to convert mechanical rotation into a pulsing direct electric current through Faraday's law of induction.

4.1.4 Hydraulic shock absorbers: This whole setup is balanced on hydraulic shock absorbers, which basically follows the principle "When a piston forces the fluid in a cylinder to pass through some hole, a high resistance to the movement of pistons is developed which provide the damping effect." This ensures a comfortable upward and downward movement of the footstep. Hence, reducing the sudden jerks, and providing a smooth walking experience.

\subsection{Mechanism}

- The upper plate (thread) of the footstep is set up on four hydraulics, to ensure the smooth movement of the footstep while walking over it and reducing jerks in the leg. This also ensures a smooth return of the top plate after removal of load.

- When the load is applied on the footstep, the downward movement causes the crankshaft to rotate.

- This rotation of the crankshaft is transferred to the main rod, which is supported on bearings, for a resistance free rotation of the main rod.

- The bigger wheel of the belt and pulley mechanism is rotated because of the rotation in the main rod, which then rotates the smaller wheel via the belt connection.

- This smaller wheel is directly connected to the DC generator, or the Dynamo, which results in the rotation of the dynamo.

- As the principle of the dynamo is to convert this mechanical energy into electrical energy, this rotation initiates the generation of electricity.

- The terminals of DC generator are attached to LEDs and further to batteries.

\section{COST ANALYSIS \& CALCULATIONS}

\subsection{Cost analysis}

\begin{tabular}{|l|l|l|}
\hline S. NO. & MATERIALS & COST (₹) \\
\hline 1 & Wooden planks & 300 \\
\hline 2 & Main rod & 150 \\
\hline 3 & Crankshaft & 100 \\
\hline 4 & Hydraulics & 2500 \\
\hline 5 & Bearings & 200 \\
\hline 6 & Belt \& pulley & 550 \\
\hline 7 & Dynamo & 400 \\
\hline 8 & Battery & 200 \\
\hline 9 & Led strip & 30 \\
\hline
\end{tabular}

Figure 5 Table of cost estimation

Total cost of setup $=₹ 4430$

\subsection{Calculations}

Consider a mass of $60 \mathrm{~kg}$ is applied over the footstep power generator. The length of the shaft of crank is $14 \mathrm{~cm}$. Diameter of smaller wheel is $18 \mathrm{~mm}$, which can rotate 6 times in one cycle of the footstep mechanism. Downward movement of footstep takes 


\section{EPRA International Journal of Research and Development (IJRD)

place because of applied weight and the upward motion takes place because of the hydraulics installed, to bring the step back to its initial place.

Therefore, for the current MODEL,

- $\quad$ Mass $=60 \mathrm{~kg}$ (avg human weight)

- $\quad$ Force $(\mathrm{F})=\mathrm{mg}=20 \times 9.81=588.6 \mathrm{~N}$

- $\quad$ Radius $=9 \mathrm{~mm}$

- $\quad$ Torque $(\tau)=\mathrm{r} \times \mathrm{F}(\mathrm{Nm})=\left(9 \times 10^{-3}\right) \times 196.2$

- $\quad$ Torque $(\tau)=5.3 \mathrm{Nm}$

- Now, Power $=\mathrm{T} \times(2 \pi \mathrm{N} / 60)$

- $\quad P=(5.3 \times 2 \times 3.14 \times 6) / 60$

- $\quad \mathrm{P}=3.32 \mathrm{~W}$

Suppose the footstep generator is walked over 20 times in a minute, therefore the small wheel will have a speed of 120rpm. Now, after an hour of usage,

$=$ Total power generated in an hour $=3.5-4 \mathrm{KW} / \mathrm{h}$.

\section{ADVANTAGES}

- To generate the electricity through the human foot.

- To provide electricity in rural area.

- To promote the non-conventional energy source \& save conventional energy sources.

- To store the electricity for further use.

- To produce electricity at cheapest cost.

- To reduce the dependency on piezoelectric crystal which were used in previous developments.

- To reduce the sudden jerks caused during the rebound action by the spring mechanism used in older versions.

- To enhance the longevity of the setup by replacing teeth gears with belt and pully mechanism, to reduce the wear and tear, and the maintenance cost.

\section{CONCLUSION}

In this project, we showed that this footstep power generation system can be a good alternate to produce electricity. This system is really beneficial for such households that suffer frequent electricity cuts, or in the areas where electricity is still not available. Also, as the major part of electricity is generated by fossil fuels that keeps polluting our planet on a daily basis, this is an eco-friendly way of generating electricity without any pollution, any sound, any smoke that makes it a system that can be installed in any public place or household without any compromises. This mechanism can be installed in staircases, can be installed in various crowded places like stations, malls, foot over bridges, pedestrian walks, parks. Also, executing this system, we can aim to reduce the dependencies on fossil fuels and can generate our own electricity for day to day uses.

As from our model, we generated around $3 \mathrm{~W}$ of electricity when a single person will walk over the step. So, when the number of people increase going over this footstep, greater will be its generation capacity. Our system generated around $4 \mathrm{KW}$ of power under the conditions of a crowded place, and we aim to increase it by improvising some mechanisms in the pulley, to make it generated even more power.

\section{REFERENCES}

1. https://www.iea.org/data-andstatistics/charts/world-gross-electricityproduction-by-source-2018

2. https://ourworldindata.org/energy-access

3. https://justenergy.com/blog/renewable-energy-vsnonrenewable-energy/

4. B.Munaswamy, Ch.Prudhvi, V.Srikanth, B.Kirankumar, E.Pradeep Kumar, "Mechanical Footstep Power Generation"; International Journal of Engineering Trends and Applications (IJETA) - Volume 5 Issue 2, Mar-Apr 2018, ISSN : 2393-9516

5. Muhammad Asad Saeed, Muhammad Hamza Tahir, Nouman Zaffar, Arslan Malik, "DESIGN OF FOOTSTEP POWERGENERATION SYSTEM USING RACK AND PINION GEARS MECHANISM" International Journal of Engineering Applied Sciences and Technology, 2019 Vol. 4, Issue 2, ISSN No. 2455-2143

6. Patel Kamlesh, Pandya Krunal, Patel Ronak, Prajapati Jaydeep, Mr. Sorathiya Mehul, "Design of Foot Step Power Generation System", 2nd International Conference on Current Research Trends in Engineering and Technology | Volume 4 | Issue 5 | Print ISSN: 2395-1990| Online ISSN : 2394-4099

7. https://www.machinedesign.com/automationiiot/article/21836482/design-essentials-how-toconvert-from-rotary-to-linear-motion

8. https://studentlesson.com/belt-pulley-definitonfunctions-types-parts-working/ 